\title{
ASSESSMENT OF HEALTH-RELATED QUALITY OF LIFE (HRQL) IN LOW- BACK PAIN PATIENTS BEFORE AND AFTER VAX-D DISC DECOMPRESSION TREATMENT. ANALYSIS USING THE COMPUTER-ASSISTED ANALYTIC HIERARCHY PROCESS (AHP)
}

\author{
Dr Ivan Naumov, Cyberspace Solutions, Inc., Pittsburgh, PA, USA and Fisioterapia Center, Rome, Italy, Dr. Albert \\ Mancini, Fisioterapia Center, Rome, Italy and Cyberspace Solutions, Inc., Pittsburgh, PA, USA, Dr. Kenneth Vinton, Pain \\ Relief \& Wellness Strategies Center, Grove City, PA, USA, James Kittelberger, PT, MS, Physical Therapy Center, Mt. \\ Lebanon, PA, USA, Professor Thomas Saaty, University of Pittsburgh, Pittsburgh, PA, USA
}

\begin{abstract}
Since the early 1990s, the vertebral axial decompression (VAX-D) spinal disc decompression therapy has been successfully implemented in the treatment of patients with low-back pain. Multiple clinical studies have demonstrated that this non-invasive treatment is an effective therapy for the management of low-back pain due to various pathologic conditions, including failed spinal surgery. The goal of this multi-center, international study was to both evidence and quantify the impact of the VAX-D therapy on the health-related quality of life (HRQL) in a sample of 105 patients, 49 male (average age 49.06 years) and 56 female (average age 48.23 years). These patients received a minimum of three, but usually not more than ten VAX-D treatment sessions of 20-30 min duration each, prior to being assessed for HRQL outcomes. Twelve HRQL assessment criteria were chosen through health careprovider and patient-selected input, related to pain intensity, personal care, lifting, walking sitting, standing, sleeping, sex life, social life, travel, job/home-duty performance, and range of motion -- and incorporated in an AHP model using DecisionLens analytic hierarchy process (AHP) software. Our results demonstrate that this FDA-approved treatment has improved the overall HRQL in all patients, regardless of gender. The overall HRQL before treatment commenced was 0.432127 in males and 0.442481 , on a ratio scale of $0-1$, where 1 was the worst possible criteria assessment/outcome and 0 was the most positive. The overall HRQL after treatment ended was 0.0391147 (90.95\% improvement) in males and 0.116742 (73.62\% improvement) in females, the overall positive VAX-D effect being more pronounced in males. The VAX-D therapy improved the HRQL in all criteria categories, in both male and female patients. This provides evidence of significant personal and public-health benefits that this relatively low-cost, efficient treatment helps most patients with various low-back pain pathology and establishes it as a very valuable alternative to costly surgical low-back pain treatment whenever possible.
\end{abstract}

Keywords: Health-related quality of life (HRQL), VAX-D disc decompression, AHP.

\section{Introduction}

Vertebral axial decompression (VAX-D) disc decompression therapy has been successfully implemented in the treatment of patients with low-back pain since the early 1990s. Multiple clinical studies have demonstrated that VAX-D is an effective treatment for the management of chronic lowback pain due to posterior facet syndromes, degenerated lumbar discs, subligamental disc herniations - at one or more levels, lumbar and/or sciatic nerve compression, extruded herniations, failed back surgery (laminectomy, disectomy), bulging discs (single or multi-level), etc. The analytic hierarchy process (AHP) is a powerful general decision-making and assessment methodology, accepted worldwide. It is based on multi-criteria evaluation, where each criterion carries a specific relative weight with respect to the final assessment goal or, as in our case, health outcomes related to health- 
related quality of life (HRQL) improvements. AHP has been successfully utilized as an assessment tool in industry, the military, business, as well as in medical research.

\section{Literature Review}

A retrospective outcome study on 778 patients, a Phase II Randomized Controlled Trial and a study conducted in a neurosurgery practice on 142 patients all reported approximately $70 \%$ success rates and improvements in functional outcomes for patients suffering from disc-related chronic low-back pain. Other studies, even though recruiting lesser number of patients have demonstrated patient improvements in various clinical outcomes.

\section{Hypotheses/Objectives}

The goal of our study was to demonstrate that VAX-D disc decompression therapy improves the HRQL in patients with low-back pain, using an evidence-based approach and health outcomes. A secondary goal was to quantify the improvement in the overall quality of life and specifically HRQL for each of the $12 \mathrm{HRQL}$ assessment criteria, chosen through health care-provider and patientselected input, related to pain intensity, personal care, lifting, walking sitting, standing, sleeping, sex life, social life, travel, job/home-duty performance, and range of motion.

\begin{tabular}{|l|l|}
\hline Hypothesis 1 & $\begin{array}{l}\text { The VAX-D therapy will significantly decrease the combined negative } \\
\text { outcome of each of the HRQL criteria }\end{array}$ \\
\hline Hypotheses 2-13 & $\begin{array}{l}\text { The VAX-D therapy will significantly decrease the negative treatment } \\
\text { outcome of each HRQL criterion }\end{array}$ \\
\hline
\end{tabular}

\section{Research Design/Methodology}

All 105 patients were treated on VAX-D tables manufactures by VAX-D Medical Technologies, Palm Harbor, FL 34685, USA. VAX-D works by interchangeably stretching and relaxing the lower spine, thereby relieving pressure on spinal structures that cause low back pain.

Fig. 1. Illustration of a VAX-D treatment table with patient receiving a treatment

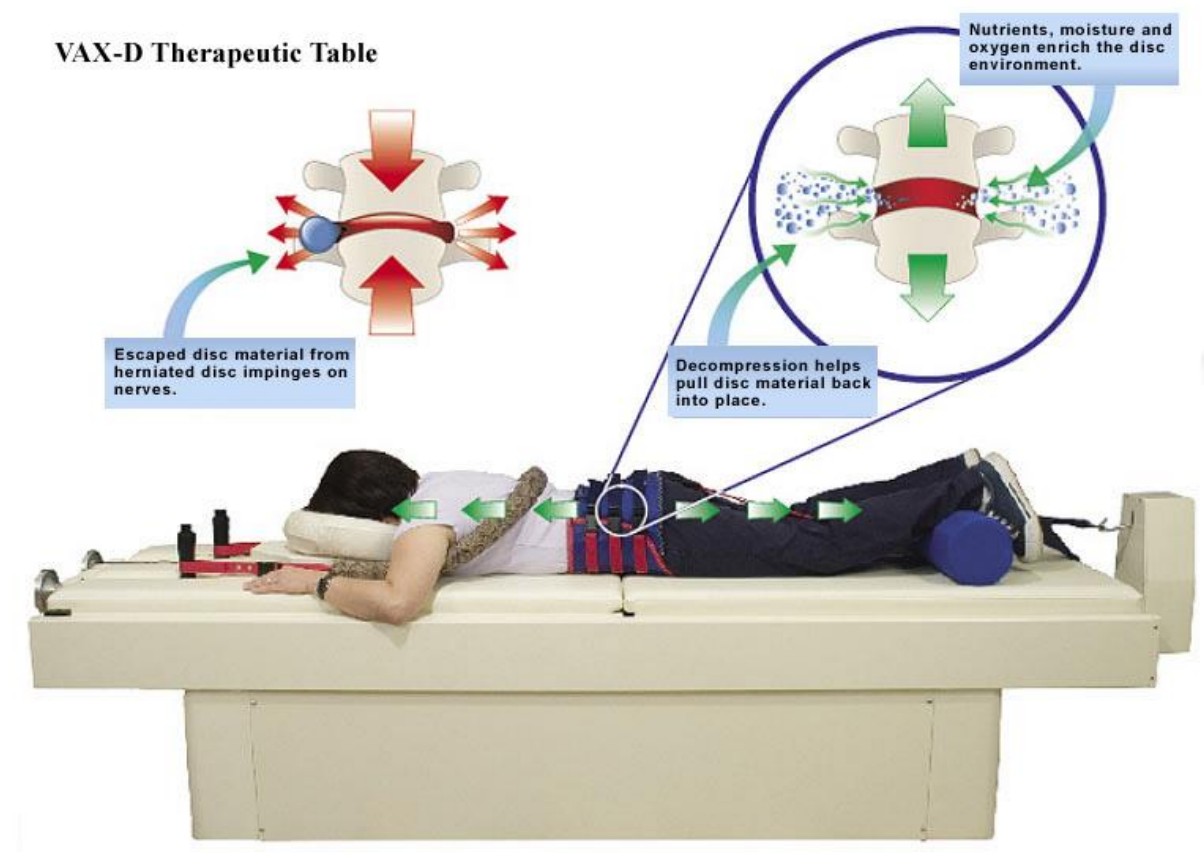


DecisionLens AHP software, created by DecisionLens, Arlington, VA, USA, was utilized in the AHP model creation and data entry. All statistical analysis was performed utilizing STATA 14 software package, developed by StataCorp, Collega Station, TX, USA. Data from the DecisionLens model was exported to Microsoft Excel for initial preliminary statistical analysis and then to STATA 14 software.

Fig.2. The AHP model employed in the assessment of HRQL before and after VAX-D therapy, as created in DecisionLens AHP software

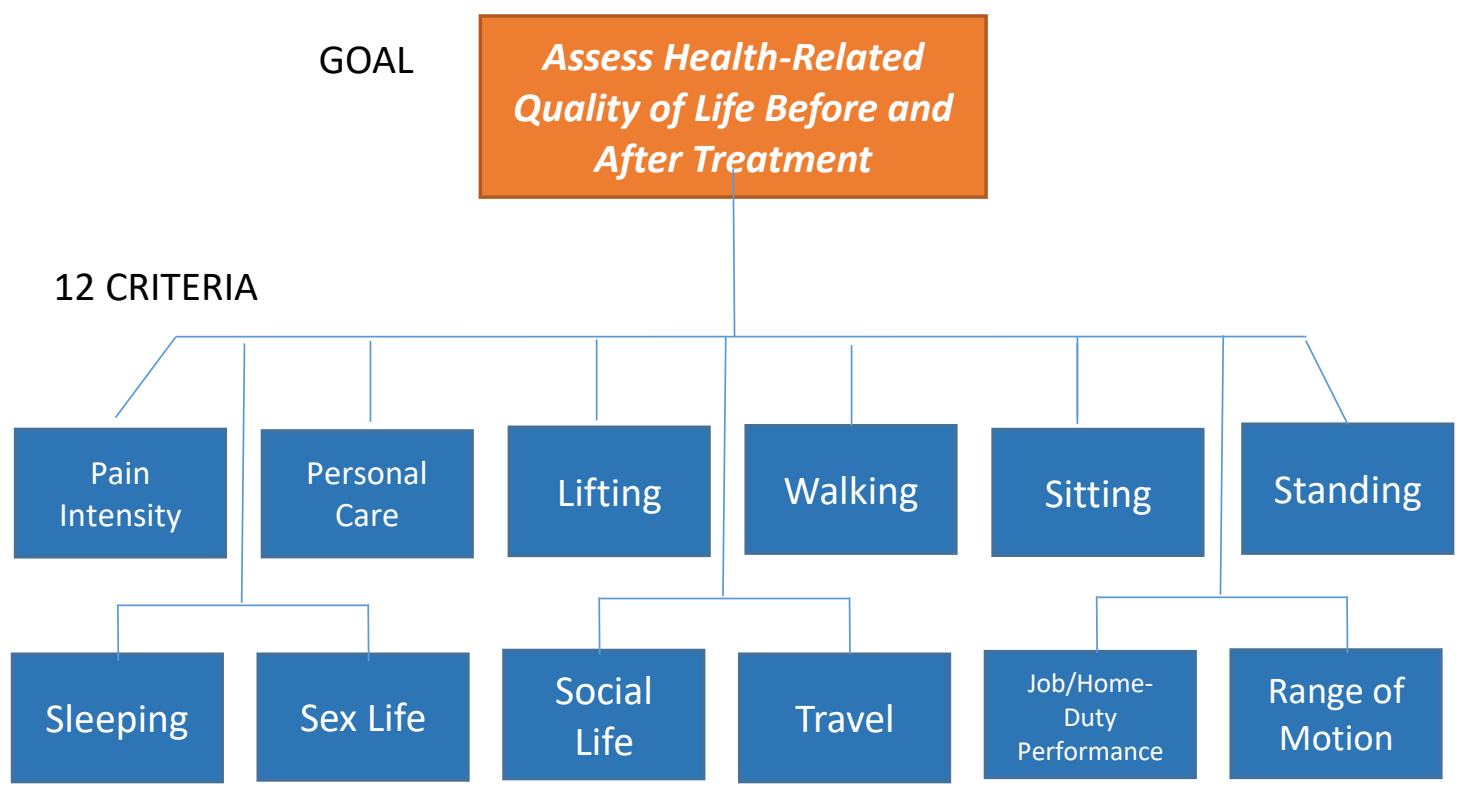

Fig. 3 The scale ratings utilized in the DecisionLens AHP model, for "pain intensity", one of the 12 criteria

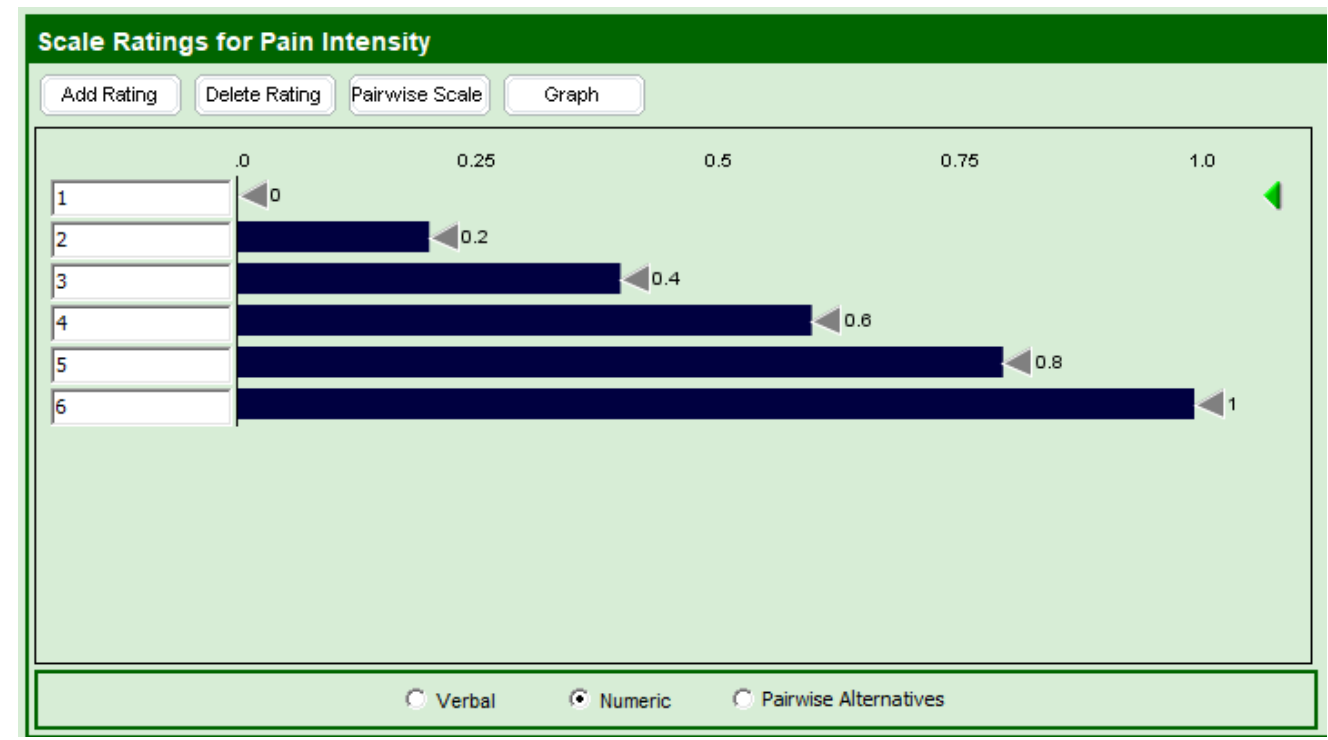

\section{Data/Results/Model Analysis}

Table 1 and Table 2, respectively, show the correlation coefficients among the main variables of interest in the study before/after the treatment. Correlations that are statistically significant at $\mathrm{p}<0.05$ are represented with an asterisk. 
Table 1. Correlation matrix of HRQL criteria/variables before VAX-D treatment

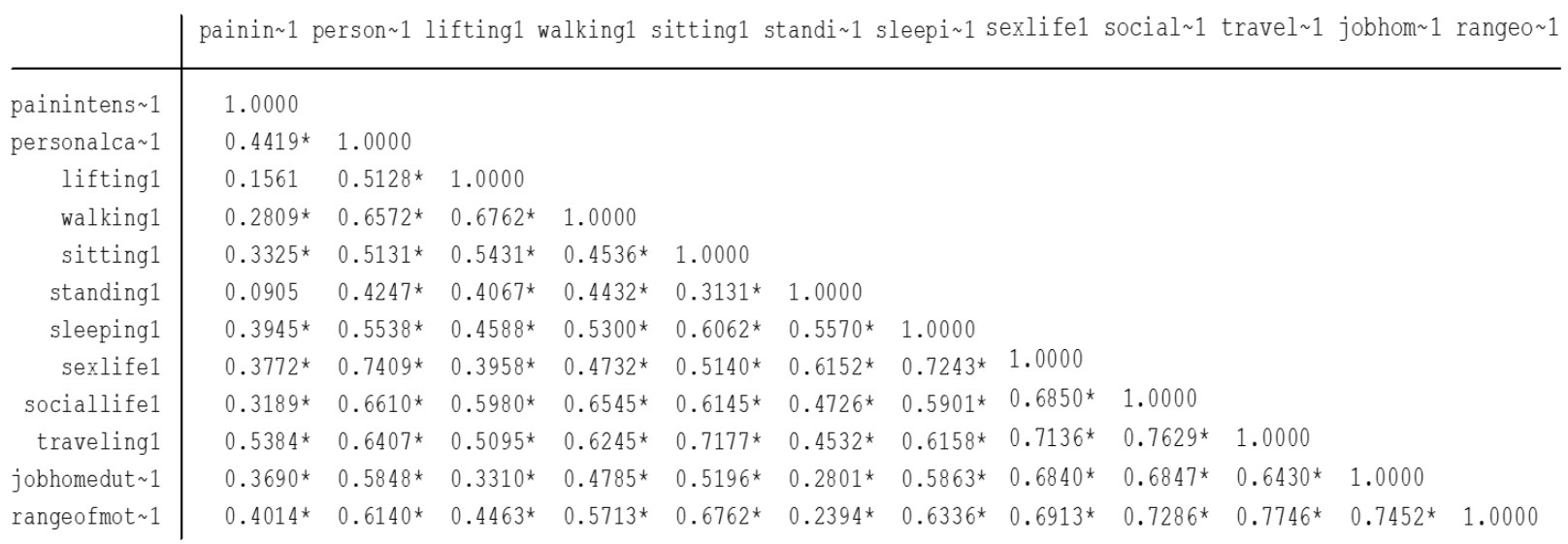

Table 2. Correlation matrix of HRQL criteria/variables after VAX-D treatment

\begin{tabular}{|c|c|c|c|c|c|c|c|c|c|c|c|c|}
\hline & painin 2 & son $\sim 2$ & ing 2 & $1 \mathrm{king} 2$ & ing2 & andi $\sim 2$ & $1 \sim 2$ & lifel & a $1 \sim 1$ & $e 1 \sim 1$ & $m \sim 1$ & \\
\hline painintens 2 & 1.0000 & & & & & & & & & & & \\
\hline personalca 2 & $0.5938 *$ & 1.0000 & & & & & & & & & & \\
\hline lifting 2 & $0.4701 \star$ & $0.7536^{\star}$ & 1.0000 & & & & & & & & & \\
\hline walking2 & $0.4324 *$ & 0.5996 * & $0.5446^{*}$ & 1.0000 & & & & & & & & \\
\hline sitting2 & 0.1319 & 0.1552 & $0.2582^{\star}$ & $0.4423^{*}$ & 1.0000 & & & & & & & \\
\hline standing2 & $0.2404 *$ & 0.4677 * & 0.4454 * & $0.6028 *$ & $0.5849 *$ & 1.0000 & & & & & & \\
\hline sleeping2 & 0.3472 * & $0.5441 *$ & $0.4296^{*}$ & $0.5943^{*}$ & 0.4788 * & $0.6444^{\star}$ & 1.0000 & & & & & \\
\hline sexlife2 & 0.1997 & $0.5656^{*}$ & $0.4580^{*}$ & $0.7163^{*}$ & $0.7550 *$ & $0.7065^{\star}$ & $0.6746^{\star}$ & 1.0000 & & & & \\
\hline sociallife2 & $0.6957 \star$ & $0.7669 *$ & $0.7202^{x}$ & $0.6786^{*}$ & $0.4595^{*}$ & 0.5373 * & $0.6182^{\star}$ & $0.6076^{x}$ & 1.0000 & & & \\
\hline traveling2 & $0.3216^{\star}$ & $0.2873 *$ & $0.4084^{*}$ & $0.6214^{\star}$ & 0.7951 * & $0.6190^{x}$ & $0.6461^{\star}$ & $0.7283^{\star}$ & $0.6731^{\star}$ & 1.0000 & & \\
\hline jobhomedut 2 & 0.1180 & 0.1298 & 0.1871 & $0.4004^{\star}$ & $0.6253^{*}$ & $0.4151^{\star}$ & $0.5280^{*}$ & $0.6213^{*}$ & $0.3899^{*}$ & $0.6495^{\star}$ & 1.0000 & \\
\hline rangeo fmo $t \sim 2$ & $0.4892^{\star}$ & 0.5554 * & $0.6069^{*}$ & $0.7926^{\star}$ & $0.5726^{\star}$ & $0.5327^{\star}$ & $0.6212^{\star}$ & $0.6579 *$ & $0.7723^{*}$ & 0.7154 * & $0.5317^{\star}$ & 1.0000 \\
\hline
\end{tabular}

We ran a series of paired t-tests to evaluate the effect of the VAX-D treatment comparing mean values of each criterion/variable outcome before and after the therapy. As shown on Table 3 there is a statistically significant effect of VAX-D with the mean level of pain intensity decreasing from 0.644 to $0.113(\mathrm{t}=15.88 ; \mathrm{p}<0.0001)$

Table 3. Paired t-test analysis evaluating the combined efficacy of VAX-D therapy in all patients

\begin{tabular}{|l|c|c|c|cc|}
\hline Variable & Mean & $\begin{array}{c}\text { Standard } \\
\text { Error }\end{array}$ & $\begin{array}{c}\text { Standard } \\
\text { Deviation }\end{array}$ & \multicolumn{2}{c|}{$\begin{array}{c}\text { [9\% Confidence } \\
\text { Interval] }\end{array}$} \\
\hline Combined efficacy before VAX-D & 0.644 & 0.026 & 0.266 & 0.593 & 0.696 \\
\hline Combined efficacy after VAX-D & 0.113 & 0.025 & 0.259 & 0063 & 0.163 \\
\hline Mean difference & 0.531 & 0.334 & 0.342 & .465 & .597 \\
\hline \multicolumn{2}{|r|}{ Mean (diff) = Mean (Combined criteria before - Combined criteria after) $\mathrm{t}=15.88$} & $\mathrm{p}<0.0001$ \\
\hline
\end{tabular}

Fig. 4. Combined negative HRQL by gender, before and after VAX-D treatment (1=worst, $0=$ most positive)
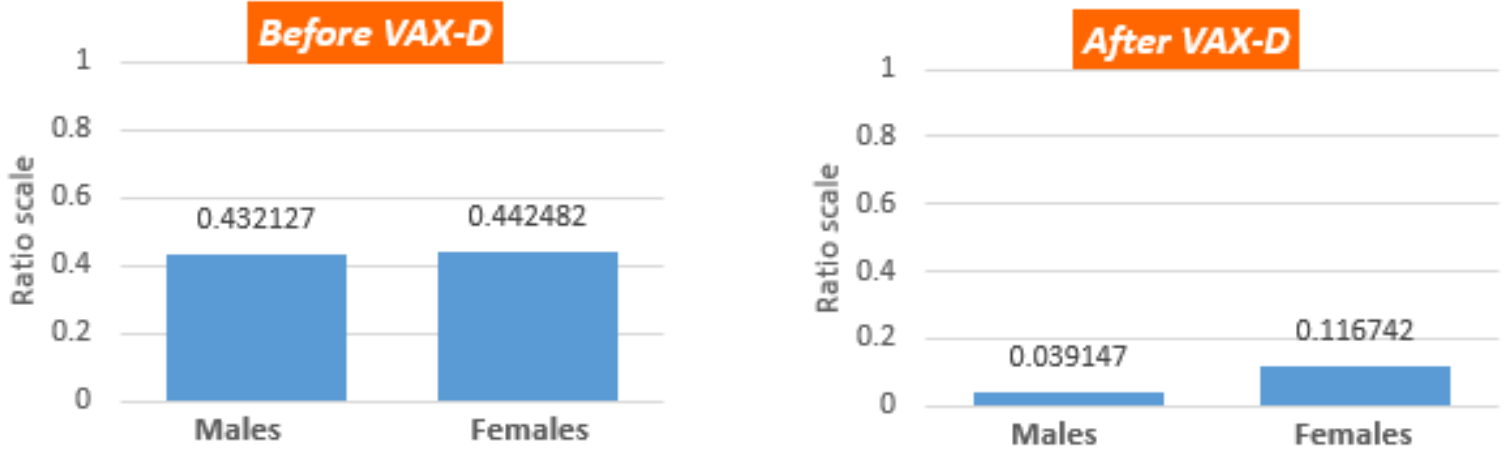


\section{Limitations}

The study was conducted both as prospective and retrospective. It is arguable that a prospective study may yield "cleaner" results. In addition, a control group receiving no treatment was not utilized, substituting for it by literature data from other studies. The ethnic/race effect was not considered in this study, nor the socio-economic status of the patients.

\section{Conclusions}

The VAX-D therapy improved the HRQL in all criteria categories, in both male and female patients. This provides evidence of significant personal and public-health benefits that this relatively low-cost, efficient treatment helps most patients with various low-back pain pathology and establishes it as a very valuable alternative to costly surgical low-back pain treatment in many clinical cases.

\section{Key References}

Sherry E, Kitchener, P Smart R. A Prospective Randomised Controlled Study of VAX-D and TENS for the Treatment of Chronic Low Back Pain. Journal of Neurological Research Vol 23, No 7, October 2001.

Tilaro F, Miskovich D. The effects of vertebral axial decompression on sensory nerve dysfunction in patients with low back pain and radiculopathy. Canadian Journal of Clinical Medicine 6(1):1-8, 1999.

Hariharan S, Dey PK, Chen DR, Moseley HS, Kumar AY. Application of analytic hierarchy process for measuring and comparing the global performance of intensive care units. Journal of Critical Care. 2005 Jun;20(2):117-24; discussion 124-5.

Shroyer AL, London MJ, Sethi GK, Marshall G, Grover FL, Hammermeister KE. Relationships between patient-related risk factors, processes, structures, and outcomes of cardiac surgical care. Conceptual models. Medical Care 1995 Oct;33(10 Suppl):OS26-34.

Saaty TL, Peniwati K. Group decision-making: Drawing out and reconciling differences. Pittsburgh, PA: RWS Publications, 2007.

Saaty TL, Zoffer HJ, Wei L. An indicator of one's life satisfaction. European Journal of Pure and Applied Mathematics. 2018 (accepted for publication). 